an attempt to avoid loss of our second strain we froze some aliquots of the original blood cultures at $-70^{\circ} \mathrm{C}$., and found on later examination that the organisms had survived.

\section{Summary}

Two cases of human vibriosis, the first to be recorded in Britain, are described. One of the vibrios isolated was a strict anaerobe, a type not previously recorded as a human pathogen. The condition should be considered whenever a pyrexia of unknown origin is being investigated, and is most likely to be diagnosed if blood cultures are taken. The organisms causing human vibriosis are related to those causing vibriosis in animals and distinct from those causing cholera in man. Non-cholera vibrio infection in man (human vibriosis) may present as a dysentery-like condition or as a pyrexial bacteraemic illness with or without localization of infection. Localization is most likely to occur in the meninges, synovial membranes, valvular endocardium, and, in pregnant women, in the foetus and foetal membranes and placenta.

I wish to thank Dr. K. Robson and Dr. T. Pilkington for permission to use their clinical notes and for access to their patients. Also Dr. Kingsley Smith for the electron microscopic studies and Miss H. Laderach for technical assistance. Special thanks are due to Dr. E. O. King, of the Communicable Disease Centre, Atlanta, Georgia, for advice, for the strains of $V$. fetus and $V$. bubulus used to prepare antisera, and for confirming the identity of the organism isolated in Case 2. Finally, I wish to thank Professor S. D. Elek and Dr. G. R. F. Hilson for advice in writing the paper.

\section{REFERENCES}

Burgert, W., and Hagstrom, J. W. C. (1964). Arch. Neurol. (Chic.), 10, 196.

Collins, H., Blevins, Ann, and Benter, Eleanor (1964). Arch. intern. Med., 113, 361

Curtis, A. H. (1913). F. infect. Dis., 12, 165
Darrell, J. H., Farrell, B. C., and Mulligan, Rosemary A. (1967). Brit. med. 7., 1

Doyle, L. P. (1948). Amer. 7. vet. Res., 9, 50.

Eden, A. N. (1962). 7. Pediat., 61, 33.

Elek, S. D. (1948). F. Path. Bact., 60, 183

Fletcher, R. D., and Plastridge, W. N. (1964), 7. Bact. 87, 352.

Hood, Marion, and Todd, J. M. (1960). Amer. F. Obstet. Gynec., 80, 506.

Jackson, J. F., Hinton, Patricia, and Allison, F. (1960). Amer. F. Med. 28, 986.

Jones, F. S., and Little, R. B. (1931). F. exp. Med., 53, 835, 845.

Kahler, R. L., and Sheldon, H. (1960). New Engl. F. Med., 262, 1218

Kiggins, E. M., and Plastridge, W. N. (1956). F. Bact., 72, 397.

Kilo, C., Hagemann, P. O., and Marzi, J. (1965). Amer. F. Med., 38, 962.

King, Elizabeth O. (1957). 7. infect. Dis., 101, 119.

1962). Ann. N.Y. Acad. Sci., 98, 700.

(1965). Personal communication.

King, Sylvia, and Bronsky, D. (1961). 7. Amer. med. Ass., 175, 1045.

King, Sylvia, and Bronsky, D. (1961).
Lecce, J. G. (1958). I. Bact., 76, 312.

Lecce, J. G. (1958). 尹. Bact., 76, 312. 1 . $18,243$.

Loeb, H., Bettag, J. L., Yung, N. K., King, Sylvia, and Bronsky, D (1966). Amer. Heart F., 71, 381 .

Loesche, W. J., Gibbons, R. J., and Socransky, S. S. (1965). F. Bact. $89,1109$.

MacFadyean, F., and Stockman, S. (1913). Report of the Departmental Committee Appointed by the Board of Agriculture and Fisheries to Enquire into Epizootic Abortion, Vol. 3. H.M.S.O., London.

Mandel, A. D., and Ellison, R. C. (1963). F. Amer. med. Ass., 185, 536

Mandel, A. D., and Ellison, R. C. (1963). 7. Amer. med. Ass.,

Middelkamp, J. N., and Wolf, H. A. (1961).

Park, R. W. A. (1961). F. appl. Bact., 24, 23

Peckham, M. C. (1958). Avian Dis., 2, 348.

Prévot, A. R. (1940). Ann. inst. Pasteur, 64, 117.

- (1948). Manuel de classification et de détermination des bactéries anaérobies, 2nd ed., p. 118 . Paris.

Reich, C. V., Heist, C." E., and Dunne, H. W. (1961). F. Bact., 82, 210.

Rhoades, H.' E. (1954). Amer. 7. vet. Res., 15, 630.

Ringen, L., and Frank, F. W. (1963). F. Bact., 86, 344.

Ritchie, A. E., Keeler, R. F., and Bryner, J. H. (1966). f. gen Microbiol., Ritchie, A. E., Keeler, R. F., and Bryner, J. H. (1966). F. gen Microbiol., Robin, L. A., Duprey, G., Jouannot, J. F., Paris, P., Magard, H., Mignard,J., and Berteau, P. (1962). Presse méd., 70, 321.

Smith, T. (1918). F. exp. Med., 28,701.

and Taylor, M. S. (1919). Ibid., 30, 299.

Spink, W. W. (1957). f. Amer. med. Ass., 163, 180.

Tunnicliff, R. (1914). F. infect. Dis., 15, 350.

Vinzent, R. (1949). Presse méd., 57, 1230.

Ward, B. Q. (1948). F. Bact., 55, 113.

Ward, B. Q. (1948). F. Bact., 55, 113. Amer. 7. Dis Child. 101, 60

Wilson, G. S., and Miles, A. A. (Topley and Wilson) 5th ed., Vol. 1, 1964, Principles of Bacteriology and Immunity. London.

\title{
Case of Human Vibriosis
}

\author{
J. H. DARRELL,* M.B., D.C.H., M.C.PATH. ; B. C. FARRELL, $\dagger$ F.I.M.L.T. \\ ROSEMARY A. MULLIGAN, $\ddagger$ M.B., B.SC., M.R.C.P.
}

Brit. med. F., 1967, 2, 287-289

Vibrio fetus was first recognized as a cause of contagious abortion in cattle by MacFadyean and Stockman (1913). Vincent et al. (1947) first described the human infection. The remaining human cases have been reported almost exclusively in the American literature. We cannot find a report from Britain.

\section{Case Report}

A male Egyptian accountant aged 28 had no history of close or repeated contact with animals. Eighteen months ago he developed abdominal distension and attacks of fever of about three days' duration, recurring at monthly intervals. Six months later he was admitted to hospital in Cairo with hepatosplenomegaly, jaundice, ascites, and a tendency to bleed; active cirrhosis was diagnosed. In the past he had had schistosomiasis and gonorrhoea, both apparently adequately treated. On examination active cirrhosis was clearly

- Lecturer, Royal Free Hospital, London. Now at Department of Bacteriology, Postgraduate Medical School of London.

t Chief Technician, Department of Microbiology, Royal Free Hospital, London.

‡ Assistant Lecturer, Department of Medicine, Royal Free Hospital, London. present. On the night of admission he passed three loose pale stools and his temperature rose to $103^{\circ} \mathrm{F} .\left(39.4^{\circ} \mathrm{C}\right.$.). There was generalized abdominal tenderness. Specimens of blood, urine, stool, and ascitic fluid were obtained for culture. His W.B.C. count was 6,800 , with $63 \%$ neutrophils. Within three days his temperature returned to normal without specific treatment, the abdominal tenderness abated, but the diarrhoea persisted. Barium-meal examination showed a dilated proximal small bowel, but sigmoidoscopy revealed no evidence of colitis. No apparently pathogenic organisms were isolated except from the blood, which yielded, from two cultures, an organism subsequently identified as a variant of $V$. fetus, resistant to the penicillins, including ampicillin, but sensitive to tetracycline, chloramphenicol, and the streptomycin group.

He had previously received tetracycline on several occasions and was now given streptomycin $0.5 \mathrm{~g}$. four times daily intramuscularly, and chloramphenicol $2 \mathrm{~g}$. daily for eight days. Six days after admission, though afebrile and still on antibiotics, he developed consolidation at his right lung base and a pleural effusion. There were no signs of pulmonary embolism or subphrenic abscess. He complained of throbbing back pain, not clearly localized, which worsened over the next three days. His temperature had remained normal after the antibiotics were discontinued (Fig. 1), but now rose to $100^{\circ} \mathrm{F}$. $\left(37.8^{\circ} \mathrm{C}\right.$.). Penicillin and streptomycin gave only 
temporary improvement and he passed into hepatic precoma. Corticosteroids were given. Daily blood cultures for the next 10 days were negative. Eight days later he complained bf neck pain, and lapsed into coma. Lumbar puncture confirmed the diagnosis of subarachnoid haemorrhage. He died eight days later. Necropsy revealed a subarachnoid blood clot over the cerebellum, the ventricles were distended with a recent blood clot, and there was haemorrhage into the cerebrum; there was no evidence of a mycotic aneurysm.

A chronic duodenal ulcer had penetrated the head of the pancreas and perforated. Fibrinous flecks on the surface of the diaphragm suggested that peritonitis had been present for two weeks or longer. The small and large bowel contained melaena faeces, and the liver showed septal cirrhosis and siderosis.

\section{Bacteriology}

The causative organism was isolated from the blood by means of the routine blood-culture set of two bottles of brain-heart infusion broth incubated in air and one of tryptose broth incubated in a candle tin. Subculture after 24 hours from the brain-heart infusion to horse-blood agar yielded, after 48 hours' anaerobic incubation without added $\mathrm{CO}_{2}$, a poor growth of pin-point colourless colonies.

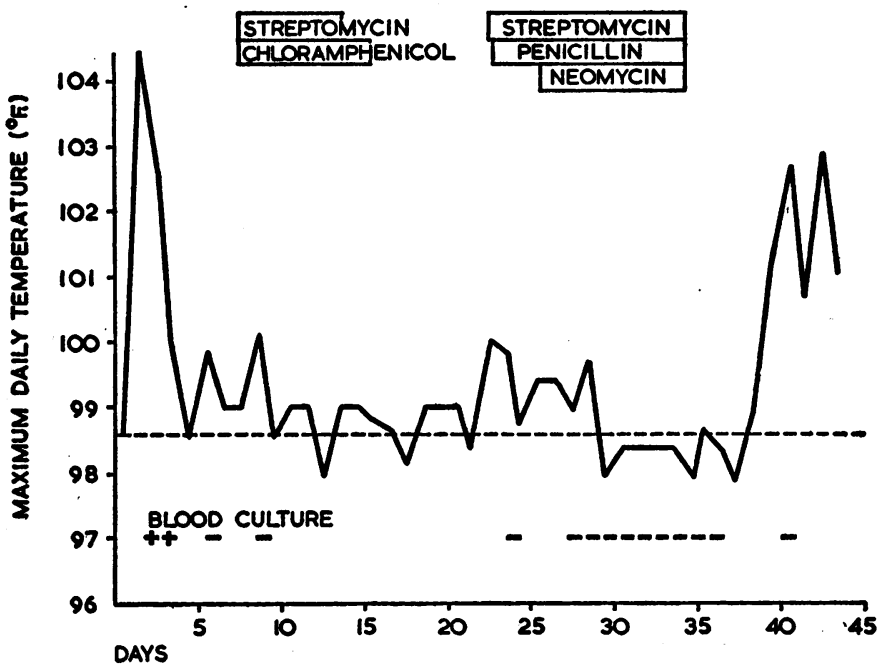

FIG. 1.-Temperature chart.

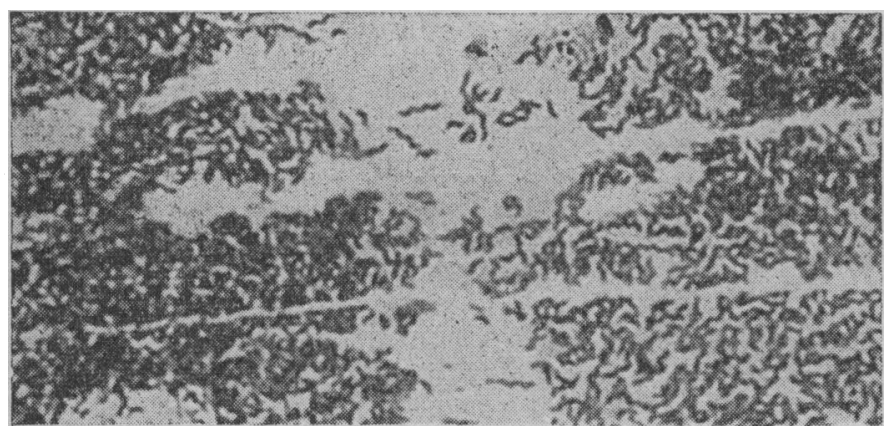

FiG. 2.-Gram-stained film of vibrio from blood-agar culture. $(x 1,400$.

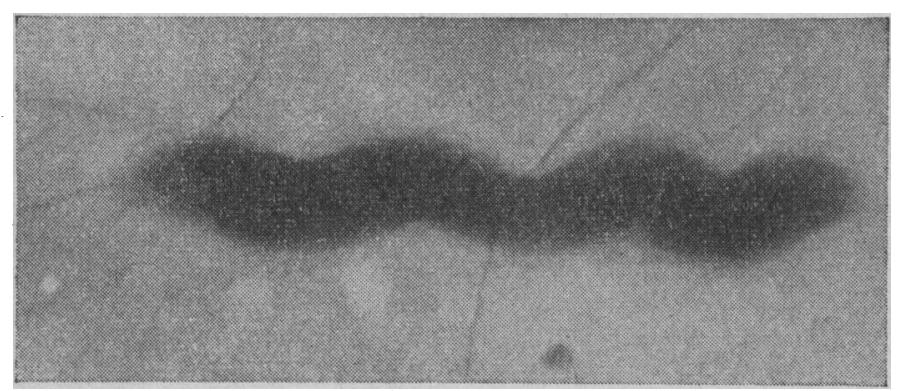

Fig. 3.-Electron micrograph showing spiral form and polar flagellum. $(\times 12,500$.
Duplicate cultures incubated in air showed no growth. However, subculture from the tryptose broth to blood agar, incubated in an atmosphere of $5 \% \mathrm{CO}_{2}$ in air, gave a better growth of pale-yellow, shiny, non-haemolytic, low convex colonies, with a slight tendency to spread. Similar growth was obtained with cultures incubated anaerobically with $2 \%$ added $\mathrm{CO}_{2}$. Gram-stained films of growth from solid media after 48 hours' incubation showed Gram-negative curved rods with moderate numbers of longer spiral forms resembling spirilla (Fig. 2). The spirals are more clearly shown in the electron micrograph (Fig. 3), which also shows the polar flagellum.

The morphology and the gaseous requirements of the organisms are characteristic of the microaerophilic vibrios, but on first isolation this group was entirely unknown to us. Thus, despite the microscopical appearance of a vibrio, the rapid positive oxidase reaction suggested we might be dealing with a Comamonas species (Vibrio alkaligenes) or with a pseudomonad other than Pseudomonas aeruginosa, and the clinical significance of the organism was in doubt until the day after its first isolation, when it was found in all three bottles of the first blood culture and one of a second. Meanwhile the discovery of a description of the organism made its significance obvious.

It was catalase-positive as well as oxidase-positive, and a peptonewater culture (incubated in $5 \% \mathrm{CO}_{2}$ ) showed very active motility with a characteristic darting movement. Biochemically the organism was quite inactive, being non-saccharolytic, indole-negative, and failing to grow on Simmons's citrate and Christensen's urea media. Hydrogen sulphide production could not be demonstrated with Kligler's medium, and a temperature optimum of $37^{\circ} \mathrm{C}$., with growth at $42^{\circ} \mathrm{C}$. but none at $22^{\circ} \mathrm{C}$, showed it to be a variant, named by King (1962) " related" vibrio, rather than $V$. fetus itself. These organisms characteristically show slight-to-moderate $\mathrm{H}_{2} \mathrm{~S}$ production when tested with lead acetate paper.

The antibiotic-sensitivity pattern of the organisms to routine discs (Oxoid Multodisk) tested on blood agar in $5 \% \mathrm{CO}_{2}$, and the minimum inhibitory concentrations of various antibiotics determined by the tube-dilution method, are shown in the Table.

\begin{tabular}{|c|c|c|c|c|}
\hline \multirow{2}{*}{\multicolumn{2}{|c|}{ : }} & \multicolumn{2}{|c|}{ Disc Sensitivity } & \multirow{2}{*}{$\begin{array}{l}\text { Minimal Inhibitory } \\
\text { Concentration } \\
\text { (Bacteriostatic Level) }\end{array}$} \\
\hline & & Conc. ( $\mu$ g.) & Result & \\
\hline $\begin{array}{l}\text { Benzylpenicillin } \\
\text { Ampicillin } \\
\text { Streptomycin } \quad \ldots \\
\text { Tetracycline } \\
\text { Chloramphenicol }\end{array}$ & $\begin{array}{l}\ddot{ } \\
\because \\
\ddot{*}\end{array}$ & $\begin{array}{r}1 \\
2 \\
10 \\
10 \\
50\end{array}$ & $\begin{array}{c}\text { Resistant } \\
\text { Sensitive } \\
\text { " }\end{array}$ & $\begin{array}{c}15 \mu \mathrm{g} . / \mathrm{ml} . \\
3.75 \\
0.75 " \\
0.5 \% \\
12.5 \%\end{array}$ \\
\hline
\end{tabular}

A specimen of serum obtained seven days after admission was tested for antibodies to the patient's organism and against a typical strain of $V$. fetus. Agglutinating antibodies to the patient's organism were present to a dilution of only 1 in 8 , but haemagglutination of group $O$ cells sensitized with the culture gave a titre of 64. Both methods gave negative results with a control serum, and the patient showed no antibodies by either method of testing against the $V$. fetus strain.

\section{Discussion}

The epidemiology of human vibriosis is obscure. In animals, where vibriosis can be an important source of economic loss, the mode of transmission is better-defined (Laing, 1960). In cattle the disease is venereal, and when artificial insemination was first introduced $V$. fetus was found to be a common cause of infertility and abortion. In parts of this country $40 \%$ of bulls were infected, but treatment with tetracycline and testmating with heifers has virtually eradicated venereal infection in cattle. In sheep the infection is still important. Here transmission is thought to be by contamination of food and water with discharges of aborted animals. Other vibrios $(V$. jejuni and $V$. coli) cause dysentery in cattle and swine. Like $V$. bubulus, a commensal strain resembling $V$. fetus, but differing in being catalase-negative and producing large amounts of $\mathrm{H}_{2} \mathrm{~S}$, these other vibrios have so far not been isolated from human infections. 
The source of infection in our case is purely a matter for speculation. Knowledge of the group is so limited and classification so unsatisfactory that it is impossible even to be certain that the organism came from an animal source. The frequency of microaerophilic vibrios as human commensals is not known, and as identification rests mainly on negative characters there may have been differences from animal strains not demonstrable by the tests used. The history of gonorrhoea is interesting, but venereal transmission has not been demonstrated in man. The possibility of ingestion in milk or uncooked meat arises, as animal vibriosis is believed to be relatively common in the Middle East. If the organism was ingested its entry to the blood stream is unlikely to have been associated with our patient's perforation and peritonitis, in which mixed infections with the predominant bowel organisms would be expected.

The blood stream is the common source of isolation of vibrios in human cases. King (1962) gives details of 29 human infections with $V$. fetus and 11 with " related" vibrio. The latter were all isolated from blood cultures, as were 23 of 29 strains of $V$. fetus. With this organism associated debilitating disease was a common predisposing factor. In two cases this was hepatic cirrhosis, which was also present in one of the previously reported cases of " related" vibrio infection. Gramnegative septicaemia is one cause of sudden deterioration in cirrhotics (Whipple and Harris, 1950 ; Martin et al., 1956). This may be due to failure to remove organisms entering the portal circulation, owing to bypass of the reticuloendothelial cells of the sinusoids because of shunting of portal blood directly into the hepatic veins via internal and external Eck fistulae.

Vibriosis in our patient presented no distinctive clinical features. It may account for recurrent fever extending over 18 months, and this could be confused with a number of chronic relapsing febrile conditions (Jackson et al., 1960). Other presentations include abortion in the few women known to have been affected, septicaemia with meningitis (Collins et al., 1964), acute septic arthritis and septicaemia (Kilo et al., 1965), and acute dysentery syndrome (Mandel and Ellison, 1963). Phlebitis is a relatively common complication (Kahler and Sheldon, 1960).

The failure of the bacteraemia to recur even when corticosteroids were given suggests that the combination of streptomycin and chloramphenicol may have been effective. The organism was most sensitive in vitro to tetracycline, which might well be the drug of choice in other cases should they occur. It was not given to our patient, as we knew he had been treated with it recently. If it is given alone, being only bacteriostatic, prolonged treatment over two or three weeks might be necessary. Alternatively, combination with streptomycin, as in the treatment of brucellosis, might be used.

Clinical bacteriologists must be familiar with organisms causing animal disease (King, 1962). An unknown number of isolates from blood cultures may be rejected as contaminants even in this country, for, while the incidence of infections in cattle has been greatly reduced, the organism still occurs in sheep. The very unimpressive growth on simple anaerobic culture is a further cogent reason for routine incubation of one bottle of a blood-culture set and subcultures from it in $5 \% \mathrm{CO}_{2}$, or at least with the addition of $\mathrm{CO}_{2}$ to anaerobic cultures.

\section{Summary}

A case of human infection with " related " vibrio is described, believed to be the first case of vibriosis due to microaerophilic vibrios reported in Britain. The infection showed no distinctive clinical features. These organisms may be discarded as contaminants, and incubation of blood cultures in an atmosphere containing added $\mathrm{CO}_{2}$ should be routinely practised. Tetracycline alone or combined with streptomycin is probably the treatment of choice.

We wish to thank Professor Sheila Sherlock for permission to publish this report ; Mr. Peter Marriott for the electron micrograph ; Dr. Joseph H. Schubert, of the C.D.C., Atlanta, Georgia, who confirmed our identification of the organism; and Dr. R. A. W. Park for his advice.

ADDENDUM.-Since the preparation of this review, McCracken and Shinefield (1966) have reported two cases of neonatal meningoencephalitis due to Vibrio fetus in a series of 71 infants studied. They also refer to a further case reported by Burgert and Hagstrom (1964). As neonates are unlikely to have had any close contact with animal sources of infection, these cases may represent autoinfection originating in the maternal gastrointestinal tract. These reports further highlight our lack of knowledge of the ecology of microaerophilic vibrios, particularly in relation to normal human bowel flora. It may well be that, using selective media and anaerobic incubation, this organism would be found in at least some normal stool specimens.

\section{REFERENCES}

Burgert, W., and Hagstrom, J. W. C. (1964). Arch. Neurol. (Chic.), 10, 196.

Collins, H. S., Blevins, Anne, and Benter, Eleanor (1964). Arch. intern. Med., 113, 361 .

Jackson, J. F., Hinton, Patricia, and Allison, F. (1960). Amer. F. Med., 28, 986.

Kahler, R. L., and Sheldon, H. (1960). New Engl. F. Med., 262, 1218. Kilo, C., Hagemann, P. O., and Marzi, J. (1965). Amer. F. Med., 38, 962 .

King, Elizabeth O. (1962). Ann. N.Y. Acad. Sci., 98, 700. Laing, J. A. (1960). Vibrio Fetus Infection in Cattle, 2nd ed. F.A.O.,

MacFadyean, F., and Stockman, S. (1913). Report of the Departmental Committee Appointed by the Board of Agriculture and Fisheries to Enquire into Epizootic Abortion, vol. 3. H.M.S.O., London.

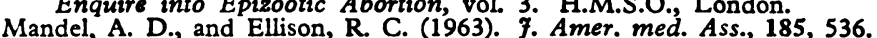
Mandel, A. D., and Ellison, R. C. (1963). F. Amer. med. Ass., 185, 536. (1956). Arch. intern. Med., 98, 8.

McCracken, G. H., jun., and Shinefield, H. R. (1966). Amer. Y. Dis. Child., 112, 33.

Vinzent, R., Dumas, J., and Picard, N. (1947). Bull. Acad. nat. Méd. (Paris), 131, 90.

Whipple, R. L., jun., and Harris, J. F. (1950). Ann. intern. Med., 33, 